\title{
Symposium review: How to implement genomic selection*
}

\author{
P. M. VanRadent (i) \\ Animal Genomics and Improvement Laboratory, USDA, Agricultural Research Service, Beltsville, MD 20705-2350
}

\begin{abstract}
Genomic selection was adopted very quickly in the $10 \mathrm{yr}$ after first implementation, and breeders continue to find new uses for genomic testing. Breeding values with higher reliability earlier in life are estimated by combining DNA genotypes for many thousands of loci using existing identification, pedigree, and phenotype databases for millions of animals. Quality control for both new and previous data is greatly improved by comparing genomic and pedigree relationships to correct parent-progeny conflicts and discover many additional ancestors. Many quantitative trait loci and gene tests have been added to previous assays that used only evenly spaced, highly polymorphic markers. Imputation now combines genotypes from many assays of differing marker densities. Prediction models have gradually advanced from normal or Bayesian distributions within trait and breed to single-step, multitrait, or other more complex models, such as multibreed models that may be needed for crossbred prediction. Genomic selection was initially applied to males to predict progeny performance but is now widely applied to females or even embryos to predict their own later performance. The initial focus on additive merit has expanded to include mating programs, genomic inbreeding, and recessive alleles. Many producers now use DNA testing to decide which heifers should be inseminated with elite dairy, beef, or sex-sorted semen, which should be embryo donors or recipients, or which should be sold or kept for breeding. Because some of these decisions are expensive to delay, predictions are now provided weekly instead of every few months. Predictions from international genomic databases are often more accurate and costeffective than those from within-country databases that were previously designed for progeny testing unless lo-
\end{abstract}

Received September 30, 2019.

Accepted January 3, 2020.

*Presented at the Joint ADSA/Interbull Session: Breeding and Genetics: Ten Years of Genomic Selection at the ADSA Annual Meeting, Cincinnati, Ohio, June 2019.

†Corresponding author: Paul.VanRaden@usda.gov cal breeds, conditions, or traits differ greatly from the larger database. Selection indexes include many new traits, often with lower heritability or requiring large initial investments to obtain phenotypes, which provide further incentive to cooperate internationally. The genomic prediction methods developed for dairy cattle are now applied widely to many animal, human, and plant populations and could be applied to many more. Key words: genomic prediction, genomic selection, DNA testing, dairy cattle

\section{INTRODUCTION}

Genomic selection differs from pedigree or phenotypic selection by directly inspecting DNA. Breeding values with higher reliability earlier in life are estimated by combining DNA genotypes for many thousands of loci with existing databases of identification, pedigree, and phenotypic information for millions of animals. Before genotypes were available for many animals or markers, researchers began deriving statistical methods and simulating prediction and selection processes (NejatiJavaremi et al., 1997; Meuwissen et al., 2001). A decade ago, the task switched to validating that genomic methods also work with real data (Mäntysaari et al., 2010) and convincing breeders that genomic predictions are accurate (VanRaden et al., 2009). Breeders of many livestock species now use genomic prediction when genotyping costs are low, the extra information gained is large, and benefits from extra progress exceed costs. A series of articles in Animal Frontiers (Ibanez-Escriche and Simianer, 2016) reviewed the status of genomic selection within several populations, and Boichard et al. (2015) reviewed many technologies used and emphasized sustainable breeding programs. Growth of genomic selection has been rapid, and many new features continue to be added $10 \mathrm{yr}$ after first implementation.

The first goal of this article is to review how genomic selection has been implemented by dairy cattle breeders and compare that with how it could have been implemented. The second goal is to suggest how breeders of other populations can successfully implement genomic selection using knowledge gained during the last decade. 


\section{DEVELOPMENT OF GENOMIC SELECTION}

\section{Genomic History}

After genetic inheritance rules were discovered (Mendel, 1866) and rediscovered (Bateson, 1900), genetic improvement programs for quantitative traits continued to use only phenotypes and pedigrees for a century and used few or no genotypes associated with the phenotypes. Breeding values in earlier decades were estimated using only an animal's own records and records of its closest relatives and eventually all relatives. In the last decade, genomic relationships were included in addition to pedigree relationships. This allows much more precise tracking of actual DNA inheritance, but the prediction methods still use mainly genetic markers because few of the causative variants are known.

Genomic selection was initially applied to males to predict progeny performance but now is widely applied to young females or even embryos to predict their own performance later in life. As a result, major dairy cattle databases in 2019 contain a hundred times more genotyped animals than in 2009 when genomic selection was beginning (Table 1). Genomic selection is also widely used for beef cattle, poultry, and swine breeding (Ibanez-Escriche and Simianer, 2016; McDougal, 2017) and to improve major crop species (Xu et al., 2014; Crossa et al., 2017; Hickey et al., 2017). Genomic prediction is now being applied to many more species (e.g., chickpeas; Roorkiwal et al., 2016). Thus, genetic principles first discovered in peas now benefit pea selection using the same tools developed for dairy and other species.

\section{DNA and Genotypes}

The first ingredient needed for genomic selection is DNA. In North America, the major AI organizations began contributing DNA from their dairy bulls to a repository at the University of Illinois (Urbana) in 1992 (Da et al., 1994) and to another repository in Beltsville, Maryland, in 1999 (Ashwell and Van Tassell, 1999). Those 2 repositories were later merged and now include DNA from more than 60,000 AI bulls.

Accurate, inexpensive genotyping made genomic selection possible for dairy cattle and other outbred populations. The initial cost of genotyping in 2008 was about $\$ 250 /$ sample with 50,000 (50K) markers but has declined over the past decade to less than $\$ 80$ for $50 \mathrm{~K}$ or less than $\$ 40$ for low-density genotyping (about 20,000 markers). Further discounts may be available when purchasing other services or genotyping many animals. The set of markers on each array has become easier to customize; however, very large orders reduce cost, and use of a common marker set makes comparing and evaluating animals simpler.

Genotype quality is very high for almost all markers; error rates are often $<0.1 \%$. Quality control for both new and previous data is greatly improved by comparing each animal's genotype to those of its parents and progeny. This process helps correct many pedigree conflicts between reported and actual parents and genotyping errors for individual markers. Historical genotypes allow discovery of pedigree relationships to many additional ancestors (such as maternal grandsires and great grandsires) that might be unknown to the animal's owner (Nani et al., 2020).

The source of DNA for cattle genotyping has shifted greatly since 2008 (Table 2). For initial development, semen was used only for reference bulls and blood was used for young bull selection. Just 2 yr later in 2010, arriving DNA samples included $82 \%$ from hair, $12 \%$ from nasal swabs, $5 \%$ from blood, $<1 \%$ from semen, and $<1 \%$ from ear punches (Wiggans et al., 2011). In 2018, samples included $14 \%$ from hair, $<1 \%$ from nasal swabs, $2 \%$ from blood, $1 \%$ from embryos, $<1 \%$ from semen, and $80 \%$ from ear punches.

The Council on Dairy Cattle Breeding (CDCB; Bowie, MD) database now includes genotypes from more than 13,000 embryos or fetuses, and selection before rather than after pregnancy could further improve rates of genetic progress. With high selection intensity, the upper limit on the genotyping market could increase from all calves born to perhaps 5 times as many embryos. Only those with the highest predictions would

Table 1. Worldwide livestock genotyping as of January 2009 and January 2019

\begin{tabular}{llrr}
\hline & & \multicolumn{2}{c}{ Animals (no.) } \\
\cline { 3 - 4 } Species & Genotype database & 2009 & 2019 \\
\hline Dairy & United States and Canada $^{1}$ & 22,344 & $3,020,000$ \\
& France $^{2}$ & 8,500 & 975,000 \\
& Germany and Austria $^{3}$ & 3,000 & 785,000 \\
& The Netherlands $^{4}$ & 6,000 & 465,000 \\
Beef and dairy & New Zealand $^{5}$ & 4,500 & 140,000 \\
Beef (Angus) & United States $^{7}$ & - & $1,500,000$ \\
Swine & Pig Improvement Company $^{8}$ & - & 550,000 \\
Poultry & Aviagen & - & 400,000 \\
& & - & $1,000,000^{10}$ \\
\hline
\end{tabular}

${ }^{1}$ Council on Dairy Cattle Breeding, Bowie, MD.

${ }^{2}$ INRA, Jouy-en-Josas, France.

${ }^{3}$ VIT, Verden, Germany; ZuchtData, Wien, Austria.

${ }^{4} \mathrm{CRV}$, Arnhem, the Netherlands.

${ }^{5}$ LIC, Hamilton, New Zealand.

${ }^{6} \mathrm{ICBF}$, Bandon, Ireland.

${ }^{7}$ American Angus Association, Saint Joseph, MO.

${ }^{8}$ PIC, Hendersonville, TN.

${ }^{9}$ Huntsville, AL.

${ }^{10}$ Annual. 
Table 2. Sources of DNA samples in 2008, 2010, and 2018 for dairy cattle genotypes used in US genomic evaluations

\begin{tabular}{|c|c|c|c|c|c|c|}
\hline \multirow[b]{2}{*}{ DNA source } & \multicolumn{2}{|c|}{2008} & \multicolumn{2}{|c|}{$2010^{1}$} & \multicolumn{2}{|c|}{2018} \\
\hline & No. & $\%$ & No. & $\%$ & No. & $\%$ \\
\hline Tissue (ear punch) & 0 & 0 & 100 & $<1$ & 579,255 & 80 \\
\hline Hair & 0 & 0 & 22,550 & 82 & 102,229 & 14 \\
\hline Blood & 623 & 11 & 1,375 & 5 & 14,656 & 2 \\
\hline Embryo & 0 & 0 & 0 & 0 & 6,188 & 1 \\
\hline Nasal swab & 0 & 0 & 3,300 & 12 & 656 & $<1$ \\
\hline Semen & 5,285 & 89 & 200 & $<1$ & 319 & $<1$ \\
\hline Unknown & 0 & 0 & 0 & 0 & 17,048 & 2 \\
\hline
\end{tabular}

${ }^{1}$ Wiggans et al. (2011).

become calves, but that strategy is not yet affordable in commercial herds, where the costs of embryo transfer, fertility loss, and genotyping exceed the selection gains.

\section{Phenotypes and Reference Populations}

A large reference population improves the reliability of genomic evaluation by matching more genotypes with phenotypes to estimate each small genetic effect. Soon after genomic selection began, several countries in Europe exchanged their Holstein reference bull genotypes (Lund et al., 2011) and Interbull (Uppsala, Sweden) exchanged Brown Swiss bull genotypes (Jorjani et al., 2012) to improve accuracy. Even if historic DNA samples are available, recent generations contribute more than earlier generations (Lourenco et al., 2014). Accuracy of genomic prediction can be improved by including DNA from females in the reference population, especially if few progeny-tested males are available (Thomasen et al., 2014; Edel et al., 2016; Su et al., 2016; Jenko et al., 2017). The US Holstein genomic reference population now includes more than 44,000 progeny-tested bulls and over 700,000 cows with milk records. Phenotypes are also needed in each new generation to determine whether actual merit agrees with predicted merit.

\section{Numbers of Variants}

Initial research on marker-assisted selection used only 367 markers from 1,415 bulls (Ashwell et al., 2004), but accuracy was too low and costs too high to implement. Similar studies with DNA from other populations and species had little success except to show that genetic inheritance is very polygenic and that more markers were needed to closely track the many genetic effects (Dekkers and Hospital, 2002). Early genomic selection among crosses of inbred lines of maize was effective and affordable (Bernardo, 1994) because just a single plant per homozygous parental line could be genotyped rather than every individual.
Numbers of potential variants to include in predictions have greatly expanded over the last decade (Table 3). Initial genomic selection in the Netherlands used around 3,000 markers in 2006 and 48,000 markers in 2007 (de Roos et al., 2009). The first genotyping assays used only evenly spaced, highly polymorphic markers (Matukumalli et al., 2009), but recent assays also now include more than 30 documented QTL and gene tests (Wiggans et al., 2016) and new markers with large effects selected from higher density chips or sequence data (van den Berg et al., 2016; VanRaden et al., 2017). Additional benefits from higher densities were often small because many of the original $50 \mathrm{~K}$ markers were already highly linked to QTL. Instead, animal breeders often opted for lower density genotyping to reduce costs.

Livestock populations share many common ancestors and thus longer DNA segments with high linkage disequilibrium that can be tracked accurately with fewer markers. In contrast, commercial human services almost always use high-density chips to discover ancestral origins. Higher-density genotyping is more useful when linkage disequilibrium is lower, such as in humans, natural populations, admixed populations, or livestock and crops without previous intense selection. Low-density genotyping may also be sufficient when inbred lines of crops are crossed (Bernardo, 1994) or when both parents and ancestors already have higherdensity genotypes.

Genotyping and sequencing have grown even more rapidly for humans than for cattle in recent years, in both numbers of individuals genotyped and variants detected (Table 4). The CDCB cooperator database had 1 million dairy cattle genotypes in August 2015 (Council on Dairy Cattle Breeding, 2015) before any human databases had 1 million genotypes; however, human databases now have tens of millions of genotypes. Human genotypes are now used in precision medicine via polygenic risk scores (Torkamani et al., 2018), which are computed from limited numbers of high-effect SNP rather than whole-genome prediction. The US Food and Drug Administration did not allow marketing 
Table 3. Numbers of variants tested in US dairy cattle and their data sources by year

\begin{tabular}{lll}
\hline Year & Variants (no.) & Data source \\
\hline$<1995$ & 0 & Only pedigrees and phenotypes \\
2003 & 367 & Microsatellite markers (not implemented) \\
2008 & 50,000 & BovineSNP50 BeadChip \\
2010 & 777,000 & High-density chip \\
2015 & $39,700,000$ & Whole genome sequencing \\
2018 & $>88,000,000$ & 1000 Bull Genomes Project \\
Future & New mutations & Sequence data for each new AI bull \\
Future & Epigenetics & External control of gene function \\
${ }^{1}$ Illumina Inc. (San Diego, CA). & \\
${ }^{2}$ http://www.1000bullgenomes.com/. &
\end{tabular}

genomic tests for human health directly to consumers until 2017. The vast amounts of human sequencing are funded either by large research grants or by corporations searching for drug targets. Currently, those funding sources are not options for livestock sequencing but sequencing costs continue to decline.

Dominant mutations can have large effects on the next generation. For example, half the daughters of the New Zealand Holstein bull Halcyon had little or no milk production after calving (Spelman, 2012; Littlejohn et al., 2014); $12 \%$ of calves sired by the Danish Holstein bull Captivo (with a new germline mutation affecting only a portion of sperm) showed chondrodysplasia (Agerholm et al., 2016; Häfliger et al., 2019); and half the progeny of the Canadian Holstein cow Rosabel had red hair color (Van Doormaal, 2013; Lawlor et al., 2014). New recessive mutations such as cholesterol deficiency, which traces back to Canadian Holstein bull Maughlin Storm, are harder to detect but may affect more animals (Kipp et al., 2016). In the future, each new bull used in AI could be sequenced to detect any new mutations not detected in previous generations.

The 1000 Bull Genomes Project (Daetwyler et al., 2014; http://www.1000bullgenomes.com/) now includes sequence data for more than 3,800 cattle worldwide and has identified over 150 million filtered variants in those cattle. In the CDCB database of 3 million genotyped animals, 118 animals already have been detected with new, large chromosome deletions not present in parents; 252 animals have XXY sex chromosomes analogous to those associated with Klinefelter syndrome in humans.

Methods to identify new mutations are becoming more exact, but methods to determine exactly which new mutations or existing variants affect traits of interest are not yet well developed. However, models can use gene annotation to improve accuracy (MacLeod et al., 2016; Fang et al., 2017). Even without new mutations or gene editing, progress could continue for many generations and reach selection limits far above current merit by combining favorable effects from independent chromosomes and haplotypes (Cole and VanRaden, 2011).

\section{Imputation}

Imputation of missing genotypes is required before estimating marker effects or breeding values. Imputation avoids reducing the marker set to the lowest common subset from multiple array; even with 1 array, each DNA source will have some randomly missing markers. Genotypes from many assays of differing marker density are now combined (Figure 1). Commonly used

Table 4. Status of human genotyping and sequencing projects as of August 2019

\begin{tabular}{llcc}
\hline Technology & Genotype database & $\begin{array}{c}\text { People genotyped } \\
\text { (millions) }\end{array}$ & $\begin{array}{c}\text { Variants genotyped } \\
\text { (millions) }\end{array}$ \\
\hline High-density SNP chip & AncestryDNA $^{1}$ & $>15$ & 0.67 \\
& 23 andMe $^{2}$ & $>10$ & 0.50 \\
Whole genome sequence & UK Biobank $^{3}$ & 0.63 & 0.60 \\
TOPMed & $>0.6$ & 463 \\
High-density SNP imputed to sequence & Illumina $^{5}$ & 500 & 500 \\
\hline
\end{tabular}

${ }^{1}$ Ancestry.com (https://www.ancestry.com/), Lehi, UT.

${ }^{2} 23$ andMe Inc. (https://www.23andme.com/), Mountain View, CA.

${ }^{3}$ UK Biobank Participant Resource Centre (https://www.ukbiobank.ac.uk/), Division of Population Medicine, Cardiff University, Cardiff, UK.

${ }^{4}$ Trans-omics for Precision Medicine (https://www.nhlbiwgs.org/), University of Washington, Seattle, WA.

${ }^{5}$ Illumina Inc. (https://www.illumina.com/), San Diego, CA.

${ }^{6}$ University of Michigan (https://imputationserver.sph.umich.edu/), Ann Arbor, MI. 


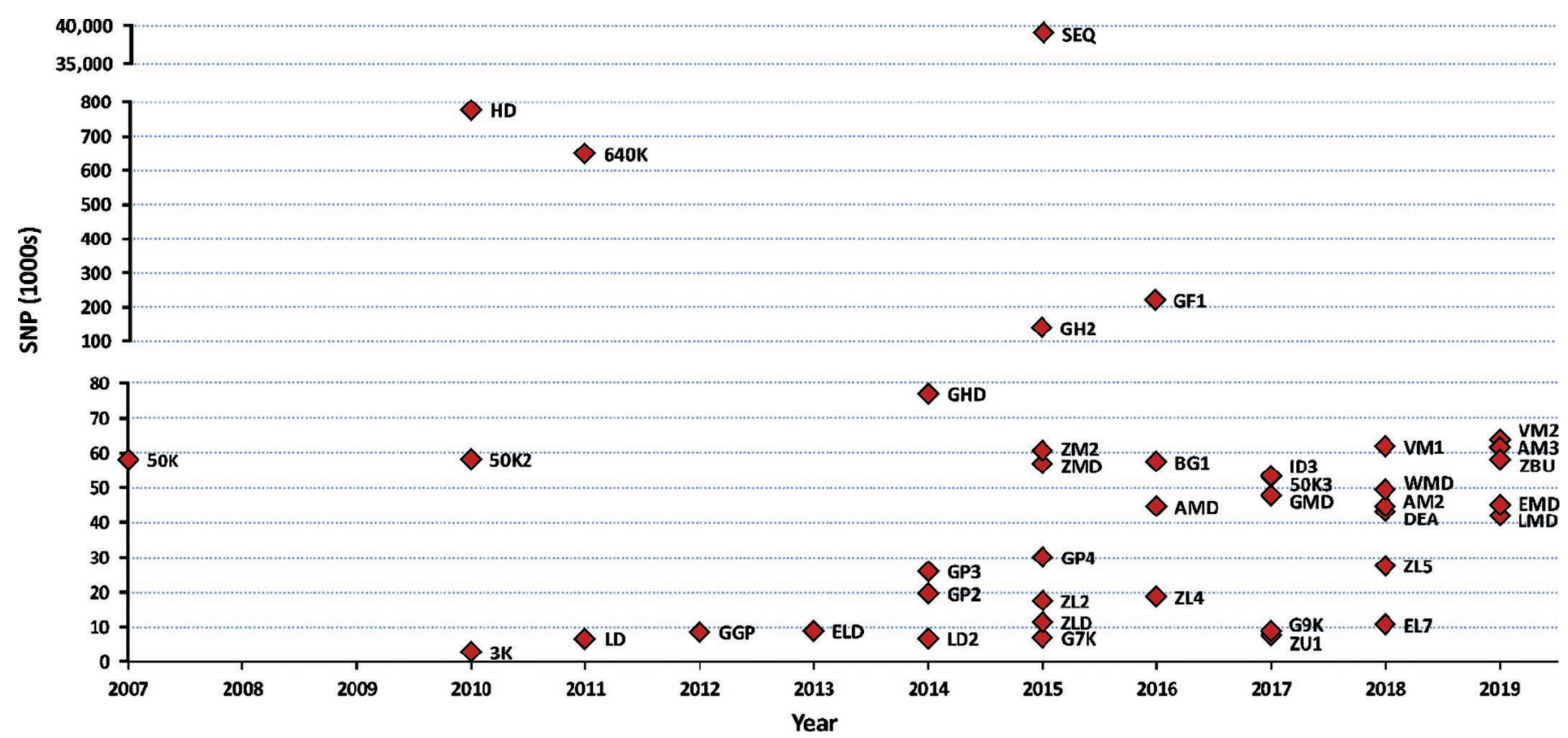

Figure 1. Introduction of genotyping arrays for genomic evaluation of dairy cattle by number of SNP included and year. Array abbreviation key is available at https://redmine.uscdcb.com/projects/cdcb-customer-service/wiki/Chips_Used_in_CDCB_Evaluation.

computer programs in animal breeding (such as FImpute; Sargolzaei et al., 2014) include general pedigrees to improve accuracy, whereas human imputation strategies often ignored pedigrees because those were not available and few relatives were genotyped.

Accuracy is affected by which animals are genotyped at which densities (Huang et al., 2012). A high-quality reference assembly (map) is required to locate variants on chromosomes (Null et al., 2019). Imputation errors reduce accuracy and can also bias predictions (Pimentel et al., 2015).

Imputation to sequence from array genotypes is used frequently in research but not yet in routine evaluations. Other options are genotyping by sequencing, which could use low-cost sequencing for a fraction of the genome (usually fewer than 3,000 SNP) but at higher read depth to improve genotyping accuracy (Gorjanc et al., 2015), or low-depth sequencing of the whole genome, which requires different statistical methods to accurately impute genotypes from the raw data (VanRaden et al., 2015).

\section{Statistical Methods and Reliability}

Prediction models using allelic relationships among markers instead of pedigree relationships were initially proposed for animals (Nejati-Javaremi et al., 1997) and plants (Bernardo, 1994). Statistical methods have gradually advanced from assuming normal or Bayes- ian distributions within breed and trait (Meuwissen et al., 2001) to single-step, multitrait, multibreed, or other more complex models (Mäntysaari et al., 2019). Multibreed models provide little benefit for pure breeds unless closely related but may be needed for crossbred selection. A few official prediction systems use haplotypes (Jónás et al., 2017) but most use multiple regression on individual SNP, which works well if numbers of SNP or linkage disequilibrium are high (Calus et al., 2008). International meta-analysis methods known as genomic multitrait across-country evaluation (MACE) were developed to combine and convert genomic predictions from each country onto the scales of all other countries (Sullivan, 2019).

Reliability of predictions is low with small populations and has not increased as quickly as theory or simulations indicated with very large reference populations. Computed and actual reliabilities should be compared using prediction error variance instead of squared correlations when the validation bulls have been preselected; actual prediction reliabilities averaged $71 \%$ for Holsteins and $65 \%$ for Jerseys (VanRaden and O'Connell, 2018). Computational methods and algorithms need to become more efficient to handle the growing data sets (Calus et al., 2015). More advanced statistical models with non-normal distributions, biological priors, or nonadditive effects often give only small advantages over simpler models unless major QTL exist. Methods of artificial intelligence do not yet 
have proven advantages over standard genomic models used by animal breeders (Bellot et al., 2018).

Many producers now use DNA testing to decide which calves should be sold immediately or kept for production or breeding. Because this decision may be expensive to delay, predictions are now provided weekly instead of every few months. Human DNA test results usually arrive in 2 to $8 \mathrm{wk}$, depending on the company and optional priority fees. Increased frequency of animal genomic evaluations has required approximate prediction methods that require less computation than reprocessing all data (Alkhoder et al., 2014; Wiggans et al., 2015). Producers also use predictions updated with more data later in life to decide which heifers and cows should be inseminated with elite dairy, beef, or sex-sorted semen and which should be embryo donors or recipients.

Previously, genetic evaluations focused on additive effects transmitted to progeny in the next generation, but animals may rank differently for their own predicted producing ability (Kelleher et al., 2015). This could include their own inbreeding (rather than expected future inbreeding of progeny), dominance effects, permanent environmental effects, health history (Yao et al., 2015), and eventually traits predicted from gene expression or other omics data in the future.

\section{APPLICATION OF GENOMIC SELECTION}

\section{New Traits}

Many new traits now evaluated often have low heritability or require large initial investments to obtain phenotypes, which provides further incentive to cooperate internationally (de Haas et al., 2015). For the least heritable traits, reliabilities for genomic predictions of young animals may now be higher than for traditional evaluations of progeny-tested bulls in the past. Selection indexes that include these new traits can increase profitability if economic values are derived correctly. Economic progress is less than optimum if valuable traits are excluded from the index or if the new traits are assigned more value than they deserve.

Genetic-by-environmental interactions are already predicted across countries by MACE and by genomic MACE (Sullivan, 2019) and could be predicted in the future for traits such as heat tolerance (Ravagnolo and Misztal, 2000; Nguyen et al., 2017), resilience (Mulder, 2016), or other herd-specific environmental effects (Schultz and Weigel, 2019). Genomic predictions for several crop species now model environmental interactions to improve accuracy by 10 to $40 \%$ (Crossa et al., 2017).

\section{Genomic Economics}

Breeders should plan how they will use information and compare costs and benefits before deciding on genetic testing options (Kaniyamattam et al., 2016). The first phase is initial investment to obtain a reference population, and the next phase is choosing candidates to test and select. Eventually, the genotyped candidates also enter the reference population so that growth is automatic if phenotyping continues. In early years when genotyping costs were high, only reference bulls and the most elite young calves were genotyped. As testing prices dropped, producers also tested heifer calves with the poorest parent averages to decide on early culling or heifers with missing pedigrees because those gained the most information from testing (Weigel et al., 2012).

Successful genomic prediction increases the benefits from other reproductive technologies such as sexed semen, beef semen, or embryo transfer that also increase selection intensity (Granleese et al., 2015; Loi et al., 2016; Fleming et al., 2018). Generation intervals were about 5 yr but have been greatly reduced to just over 2 yr (except in the dams-of-females path), because young animals have the highest average merit and now also have high reliability (García-Ruiz et al., 2016).

Genomic selection is cost effective because a single DNA sample can provide accurate predictions for many traits, ancestor confirmation or discovery, and information for herd reproductive management. The initial focus on additive merit has expanded to include recessive alleles (Adams et al., 2016), mating programs (Sun et al., 2013), genomic inbreeding, crossbreeding, and estimation of breed contributions. In contrast, estimating geographic origin of ancestors is often the primary service of human genotyping (Ancestry.com, 2018).

International databases improve prediction accuracy by increasing the reference population size compared with the within-country genetic evaluations previously designed for progeny testing, but multitrait methods and more computation may be required. Obtaining genomic predictions from an international database is usually more cost effective than computing predictions from only local data unless local breeds, conditions, or traits differ greatly from the large database. Genomic selection has greatly shifted the incentives and benefits for collecting phenotypes (Gonzalez-Recio et al., 2014) and has become even more relevant when investing in new phenotypes such as feed intake. The cost of developing a domestic system of genomic prediction in each country may be too high if accurate predictions are already available from foreign databases (Matthews et al., 2019). As a result, CDCB has provided genomic predictions to breeders in more than 50 countries for 
tens of thousands of calves in South America, Asia, and Oceania (Figure 2).

Implementation of genomic prediction proceeded quickly without many legal issues because most researchers did not patent the genetic and statistical concepts used. Patents on gene tests slowed down implementation by preventing important QTL or selected markers from being included in widely available chips. Private organizations that invest to collect data and build reference populations need to protect the value of their investments. Government organizations such as USDA previously provided evaluation services for free, but genomic prediction has become a big business that must generate revenue.

Reverse engineering could undercut the value of reference data sets by back-solving for SNP effects using only genomic predictions and genotypes without phenotypes. The process is similar to using EBV deregression and pedigrees to reverse-engineer average daughter phenotypes. Recipients of genomic evaluations calculated by CDCB must agree to "not decompile, disassemble, analyze or otherwise examine the Software and Services for the purpose of reverse engineering ..." (Council on Dairy Cattle Breeding, 2017). Such predictions might contribute nothing back to organizations that invest in collecting phenotypes. Before trading bull genotypes, some organizations also agreed not to reverse-engineer any traits evaluated only by the sending organization and not by the receiving organization. Genotype exchange agreements may state that any computed breeding values must include the country's own reference animals and not be computed for traits only in the other country's database.

\section{Biases and Mistakes}

Statistical research initially focused mainly on improving reliability of predictions but soon also focused on removing biases so that breeders could properly compare younger and older bulls (Mäntysaari et al., 2010). The small biases shown in simulations were larger with real data because of selection, preferential treatment of bull dams, nonadditive genetic effects, changing trait definitions across time, and inclusion of correlated foreign data. Biases were reduced by including polygenic effects (Liu et al., 2011), replacing parent average with pedigree index to exclude biases from elite dams (Rensing et al., 2009), adjusting the weights used for blending conventional with genomic information, or reducing heritability in conventional models. More recently, single-step models have been applied to remove further bias from genomic preselection and improve accuracy (Mäntysaari et al., 2019).

Upward biases were common in parent averages of young US AI bulls before 2009. Those biases decreased after genomic predictions were implemented, statisti-

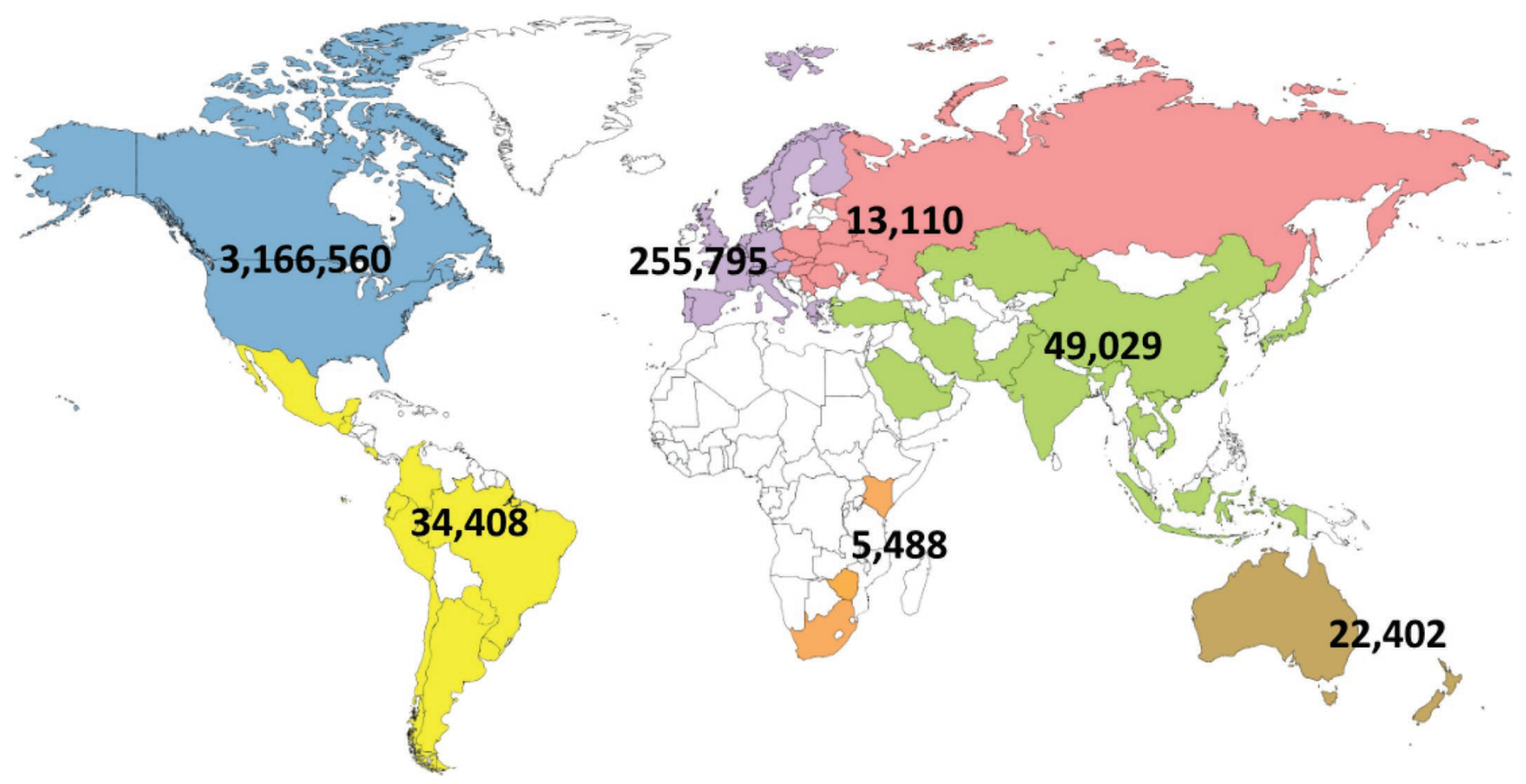

Figure 2. Numbers of genotyped dairy cattle in the 2019 US national database for genomic evaluation by global region. 
cal methods were refined, and the reference population increased (Figure 3). Before 2009, parent averages of young bulls for net merit were higher than PTA of progeny-tested bulls, but the young bulls did not actually have higher genetic merit. Since 2009, the actual advantage of the top 100 young bulls over the top 100 progeny-tested bulls for net merit improved each year with more genomic testing and intense selection of young bulls. Some small declines in later compared with initial evaluations are expected for net merit of both progeny-tested and young bulls across time because of changes in their expected future inbreeding and inclusion of new traits in net merit.

Despite rapid genetic gains, some decisions and strategies since implementation may not have been optimal. Individual breeders could not do genomic testing of their own bulls in the first $5 \mathrm{yr}$, and in recent years many AI companies have limited the access to their best new bulls. The opposite problem can occur and has occurred when too many breeders focus on the same top young bull. Genomic inbreeding increased faster than expected because predictions are more accurate for the largest families and breeds.

When genomic testing began, every laboratory had problems matching DNA samples to the correct ID. Often, all animal genotypes on a single chip were mismatched because DNA intended for the left row was placed on the right row and vice versa. Such problems were identified statistically by counting parent mismatches per chip when pedigree was available and later solved by better laboratory automation instead of hand pipetting. A similar problem occurred at the farm level when DNA samples were all shifted by 1 compared with the ID list. That problem was later solved mainly by applying an ear tag at the same time as sampling the ear tissue. Bulls used in AI are required to be genotyped again to ensure that the semen sold matches the DNA originally tested.

Transfer of genomic data was not always simple due to the variety of formats used, causing occasional data processing mistakes. Other countries often require a format different than the national format. Revised SNP names and SNP numbers even for the same chip caused occasional mismatches of input files. Different chip manufacturers may report different allele coding. Laboratories need to decide whether or how to store DNA or extracted DNA for later reprocessing and how to manage efficient, accurate retrieval. Because individual genotypes were usually determined accurately, raw allelic intensity ratios were not stored nationally, but could be helpful in resolving marker problems or detecting copy number variants.

Initial investments could have been larger in computing resources, genotyping historical US bulls, testing

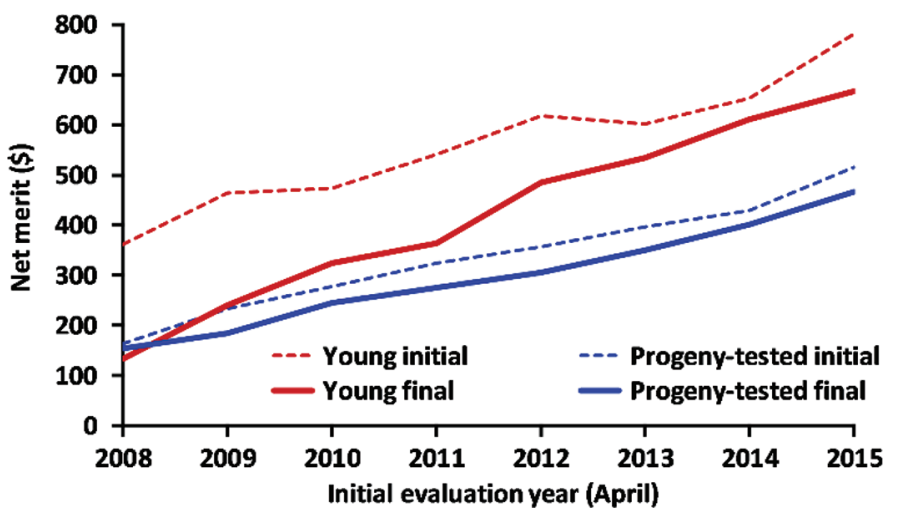

Figure 3. Initial and final (April 2019) PTA averages of the top 100 US AI Holstein bulls for net merit adjusted to the 2019 genetic base; young bulls had no milking daughters, and progeny-tested bulls had 100 daughters or more.

high-density chips, sequencing, and collecting data for additional traits. Some of these seemed costly at the time, but benefits increased quickly with the rapid growth of genotyping. Because genomic databases grew faster than computer resources, programs had to be revised many times to improve efficiency. Finding a common SNP subset is more difficult with the wide variety of chips in use, and each chip requires additional manufacturing expense. Nearly 20,000 historical, progeny-tested bulls with DNA in the Cooperative Dairy DNA Repository have not yet been genotyped with any chip but would add less information to the reference population now than 10 yr ago. The most important bulls were genotyped so that most ancestor bulls are genotyped in the 10-generation pedigrees of currently registered animals.

\section{Strategies for Other Populations}

Genomic selection can be applied to additional traits, breeds, and species, but implementation is much easier for those with historical databases and well-developed international markets for elite breeding stock. Researchers should begin by simulating potential reliabilities and calculating expected returns on investment before implementing genomic selection. This may first require collecting sufficient phenotypes and pedigrees to estimate trait parameters and sufficient genotypes to determine population structure and check accuracy of the pedigrees. Permanent, unique national or international ID are needed, preferably using standard methods approved by the International Committee on Animal Recording. Deciding which traits to phenotype and to improve is also a key step. To get started, large investments may be required to build reference populations, design genotyping tools, test predictions, and 
develop services. Such investments may or may not pay off depending on the reliability achieved, the size of the potential market, and the number of other organizations offering similar, better, or cheaper services. Progress is faster in many cases with cooperation than with only competition.

Further application of genomics combined with reproductive tools, genotype-by-environment interactions, across-breed prediction, sequencing, and bioinformatics should further speed progress for dairy cattle and other species in the next decade. The genetic trend for lifetime net merit of Holstein dairy cattle has already doubled with a huge return on investment during the last decade (Rexroad et al., 2019).

\section{CONCLUSIONS}

Genomic prediction methods developed for dairy cattle are now applied widely to many other animal, human, and plant populations. The DNA predictions adopted 10 yr ago have improved rapidly. Accuracy improves as data sets expand and more traits are included. Large numbers of genotypes and phenotypes are needed to detect the many small effects of individual genes. Genomic information also now has many new uses such as for pedigree discovery, mating programs, and guiding reproductive management. Future predictions will use more gene tests discovered from sequence data and more international genotypes. As costs decline and data sets expand, genomic selection will be applied to new populations and species.

\section{ACKNOWLEDGMENTS}

The author thanks the Council on Dairy Cattle Breeding (CDCB, Bowie, MD) and dairy industry cooperators for supplying data; Jeff O'Connell (University of Maryland School of Medicine, Baltimore), Juan Nani (USDA, Beltsville, MD), Duane Norman (CDCB), and Daniel Gianola (University of Wisconsin, Madison) for helpful comments; and Suzanne Hubbard (USDA, Beltsville, MD) for technical editing. The author was supported by appropriated project 8042-31000-002-00, "Improving Dairy Animals by Increasing Accuracy of Genomic Prediction, Evaluating New Traits, and Redefining Selection Goals," of the USDA Agricultural Research Service. Mention of trade names or commercial products in this article is solely for the purpose of providing specific information and does not imply recommendation or endorsement by the USDA. The USDA is an equal opportunity provider and employer. The author has not stated any conflicts of interest.

\section{REFERENCES}

Adams, H. A., T. S. Sonstegard, P. M. VanRaden, D. J. Null, C. P. Van Tassell, D. M. Larkin, and H. A. Lewin. 2016. Identification of a nonsense mutation in APAF1 that is likely causal for a decrease in reproductive efficiency in Holstein dairy cattle. J. Dairy Sci. 99:6693-6701. https://doi.org/10.3168/jds.2015-10517.

Agerholm, J. S., F. Menzi, F. J. McEvoy, V. Jagannathan, and C. Drögemüller. 2016. Lethal chondrodysplasia in a family of Holstein cattle is associated with a de novo splice site variant of COL2A1. BMC Vet. Res. 12:100. https://doi.org/10.1186/s12917-016-0739 -z.

Alkhoder, H., Z. Liu, T. Bach, E. Pasman, and F. Reinhardt. 2014. A continuous genomic evaluation system for German Holsteins. Interbull Bull. 48:100-104.

Ancestry.com. 2018. Ethnicity estimate 2018 white paper. Accessed Dec. 23, 2019. https://www.ancestrycdn.com/dna/static/images/ ethnicity/help/WhitePaper_Final_091118dbs.pdf.

Ashwell, M. S., D. W. Heyen, T. S. Sonstegard, C. P. Van Tassell, Y. Da, P. M. VanRaden, M. Ron, J. I. Weller, and H. A. Lewin. 2004. Detection of quantitative trait loci affecting milk production, health, and reproductive traits in Holstein cattle. J. Dairy Sci. 87:468-475. https://doi.org/10.3168/jds.S0022-0302(04)73186-0.

Ashwell, M. S., and C. P. Van Tassell. 1999. The Cooperative Dairy DNA Repository - A new resource for quantitative trait loci detection and verification. J. Dairy Sci. 82(Suppl. 1):54. (Abstr.)

Bateson, W. 1900. Hybridisation and cross-breeding as a method of scientific investigation. J. R. Hort. Soc. 24:59-66.

Bellot, P., G. de los Campos, and M. Pérez-Enciso. 2018. Can deep learning improve genomic prediction of complex human traits? Genetics 210:809-819. https://doi.org/10.1534/genetics.118.301298.

Bernardo, R. 1994. Prediction of maize single-cross performance using RFLPs and information from related hybrids. Crop Sci. 34:20-25. https://doi.org/10.2135/cropsci1994.0011183X003400010003x.

Boichard, D., V. Ducrocq, and S. Fritz. 2015. Sustainable dairy cattle selection in the genomic era. J. Anim. Breed. Genet. 132:135-143. https://doi.org/10.1111/jbg.12150.

Calus, M. P. L., T. H. E. Meuwissen, A. P. W. de Roos, and R. F. Veerkamp. 2008. Accuracy of genomic selection using different methods to define haplotypes. Genetics 178:553-561. https://doi .org/10.1534/genetics.107.080838.

Calus, M. P. L., J. Vandenplas, and J. Ten Napel. 2015. Ever-growing data sets pose (new) challenges to genomic prediction models. J. Anim. Breed. Genet. 132:407-408. https://doi.org/10.1111/jbg .12192 .

Cole, J. B., and P. M. VanRaden. 2011. Use of haplotypes to estimate Mendelian sampling effects and selection limits. J. Anim. Breed. Genet. 128:446-455. https://doi.org/10.1111/j.1439-0388 .2011.00922.x.

Council on Dairy Cattle Breeding. 2015. CDCB cooperator database genotypes 1 millionth animal. Accessed Dec. 26, 2019. https:// queries.uscdcb.com/News/CDCB\%20Industry\%20Event\%2009 $\% 2029 \% 2015$.pdf.

Council on Dairy Cattle Breeding. 2017. Research Recipient Agreement for Software and Services. Accessed Dec. 23, 2019. https: //redmine.uscdcb.com/attachments/download/657/COLUMBUS -\%231779815-v2-CDCB\%20Research\%20Recipient\%20Agreement .pdf.

Crossa, J., P. Pérez-Rodríguez, J. Cuevas, O. Montesinos-López, D. Jarquín, G. de los Campos, J. Burgueño, J. M. González-Camacho, S. Pérez-Elizalde, Y. Beyene, S. Dreisigacker, R. Singh, X. Zhang, M. Gowda, M. Roorkiwal, J. Rutkoski, and R. K. Varshney. 2017. Genomic selection in plant breeding: Methods, models, and perspectives. Trends Plant Sci. 22:961-975. https://doi.org/10 .1016/j.tplants.2017.08.011.

Da, Y., M. Ron, A. Yanai, M. Band, R. E. Everts, D. W. Heyen, J. I. Weller, G. R. Wiggans, and H. A. Lewin. 1994. The Dairy Bull DNA Repository: A resource for mapping quantitative trait loci. Proc. 5th World Congr. Genet. Appl. Livestock. Prod. 21:229-232.

Daetwyler, H. D., A. Capitan, H. Pausch, P. Stothard, R. van Binsbergen, R. F. Brøndum, X. Liao, A. Djari, S. C. Rodriguez, C. Grohs, 
D. Esquerré, O. Bouchez, M.-N. Rossignol, C. Klopp, D. Rocha, S. Fritz, A. Eggen, P. J. Bowman, D. Coote, A. M. Chamberlain, C. Anderson, C. P. Van Tassell, I. Hulsegge, M. E. Goddard, B. Guldbrandtsen, M. S. Lund, R. F. Veerkamp, D. A. Boichard, R. Fries, and B. J. Hayes. 2014. Whole-genome sequencing of 234 bulls facilitates mapping of monogenic and complex traits in cattle. Nat. Genet. 46:858-865. https://doi.org/10.1038/ng.3034.

de Haas, Y., J. E. Pryce, M. P. L. Calus, E. Wall, D. P. Berry, P. Løvendahl, N. Krattenmacher, F. Miglior, K. Weigel, D. Spurlock, K. A. Macdonald, B. Hulsegge, and R. F. Veerkamp. 2015. Genomic prediction of dry matter intake in dairy cattle from an international data set consisting of research herds in Europe, North America, and Australasia. J. Dairy Sci. 98:6522-6534. https://doi .org/10.3168/jds.2014-9257.

de Roos, A. P. W., C. Schrooten, E. Mullaart, S. van der Beek, G. de Jong, and W. Voskamp. 2009. Genomic selection at CRV. Interbull Bull. 39:47-50.

Dekkers, J. C. M., and F. Hospital. 2002. The use of molecular genetics in the improvement of agricultural populations. Nat. Rev. Genet. 3:22-32. https://doi.org/10.1038/nrg701.

Edel, C., E. C. G. Pimentel, L. Plieschke, R. Emmerling, and K.-U. Götz. 2016. Short communication: The effect of genotyping cows to improve the reliability of genomic predictions for selection candidates. J. Dairy Sci. 99:1999-2004. https://doi.org/10.3168/jds .2015-10246.

Fang, L., G. Sahana, P. Ma, G. Su, Y. Yu, S. Zhang, M. S. Lund, and P. Sørensen. 2017. Use of biological priors enhances understanding of genetic architecture and genomic prediction of complex traits within and between dairy cattle breeds. BMC Genomics 18:604. https://doi.org/10.1186/s12864-017-4004-z.

Fleming, A., E. A. Abdalla, C. Maltecca, and C. F. Baes. 2018. Invited review: Reproductive and genomic technologies to optimize breeding strategies for genetic progress in dairy cattle. Arch. Anim. Breed. 61:43-57. https://doi.org/10.5194/aab-61-43-2018.

García-Ruiz, A., J. B. Cole, P. M. VanRaden, G. R. Wiggans, F. J. Ruiz-López, and C. P. Van Tassell. 2016. Changes in genetic selection differentials and generation intervals in US Holstein dairy cattle as a result of genomic selection. Proc. Natl. Acad. Sci. USA 113:E3995-E4004. https://doi.org/10.1073/pnas.1519061113.

Gonzalez-Recio, O., M. P. Coffey, and J. E. Pryce. 2014. On the value of the phenotypes in the genomic era. J. Dairy Sci. 97:7905-7915. https://doi.org/10.3168/jds.2014-8125.

Gorjanc, G., M. A. Cleveland, R. D. Houston, and J. M. Hickey. 2015. Potential of genotyping-by-sequencing for genomic selection in livestock populations. Genet. Sel. Evol. 47:12. https://doi.org/10 $.1186 / \mathrm{s} 12711-015-0102-\mathrm{z}$.

Granleese, T., S. A. Clark, A. A. Swan, and J. H. J. van der Werf. 2015. Increased genetic gains in sheep, beef and dairy breeding programs from using female reproductive technologies combined with optimal contribution selection and genomic breeding values. Genet. Sel. Evol. 47:70. https://doi.org/10.1186/s12711-015-0151 -3 .

Häfliger, I. M., H. Behn, M. Freick, V. Jagannathan, and C. Drögemüller. 2019. A COL2A1 de novo variant in a Holstein bulldog calf. Anim. Genet. 50:113-114. https://doi.org/10.1111/age.12735.

Hickey, J. M., T. Chiurugwi, I. Mackay, and W. Powell., and Implementing Genomic Selection in CGIAR Breeding Programs Workshop Participants. 2017. Genomic prediction unifies animal and plant breeding programs to form platforms for biological discovery. Nat. Genet. 49:1297-1303. https://doi.org/10.1038/ng.3920.

Huang, Y., J. M. Hickey, M. A. Cleveland, and C. Maltecca. 2012. Assessment of alternative genotyping strategies to maximize imputation accuracy at minimal cost. Genet. Sel. Evol. 44:25. https://doi .org/10.1186/1297-9686-44-25.

Ibanez-Escriche, N., and H. Simianer. 2016. From the editors: Animal breeding in the genomics era. Anim. Front. 6:4-5. https://doi.org/ 10.2527/af.2016-0001.

Jenko, J., G. R. Wiggans, T. A. Cooper, S. A. E. Eaglen, W. G. L. Luff, M. Bichard, R. Pong-Wong, and J. A. Woolliams. 2017. Cow genotyping strategies for genomic selection in a small dairy cattle population. J. Dairy Sci. 100:439-452. https://doi.org/10.3168/jds .2016-11479.

Jónás, D., V. Ducrocq, and P. Croiseau. 2017. Short communication: The combined use of linkage disequilibrium-based haploblocks and allele frequency-based haplotype selection methods enhances genomic evaluation accuracy in dairy cattle. J. Dairy Sci. 100:29052908. https://doi.org/10.3168/jds.2016-11798.

Jorjani, H., J. Jakobsen, E. Hjerpe, V. Palucci, and J. Dürr. 2012. Status of genomic evaluation in the Brown Swiss populations. Interbull Bull. 46:46-54.

Kaniyamattam, K., M. A. Elzo, J. B. Cole, and A. De Vries. 2016. Stochastic dynamic simulation modeling including multitrait genetics to estimate genetic, technical, and financial consequences of dairy farm reproduction and selection strategies. J. Dairy Sci. 99:8187-8202. https://doi.org/10.3168/jds.2016-11136.

Kelleher, M. M., P. R. Amer, L. Shalloo, R. D. Evans, T. J. Byrne, F. Buckley, and D. P. Berry. 2015. Development of an index to rank dairy females on expected lifetime profit. J. Dairy Sci. 98:42254239. https://doi.org/10.3168/jds.2014-9073.

Kipp, S., D. Segelke, S. Schierenbeck, F. Reinhardt, R. Reents, C. Wurmser, H. Pausch, R. Fries, G. Thaller, J. Tetens, J. Pott, D. Haas, B. B. Raddatz, M. Hewicker-Trautwein, I. Proios, M. Schmicke, and W. Grünberg. 2016. Identification of a haplotype associated with cholesterol deficiency and increased juvenile mortality in Holstein cattle. J. Dairy Sci. 99:8915-8931. https://doi .org/10.3168/jds.2016-11118.

Lawlor, T. J., P. M. VanRaden, D. Null, J. Levisee, and B. Dorhorst. 2014. Using haplotypes to unravel the inheritance of Holstein coat color. Commun. 289 in Proc. 10th World Congr. Genet. Appl. Livest. Prod., Vancouver, BC, Canada. Am. Soc. Anim. Sci., Champaign, IL.

Littlejohn, M. D., K. M. Henty, K. Tiplady, T. Johnson, C. Harland, T. Lopdell, R. G. Sherlock, W. Li, S. D. Lukefahr, B. C. Shanks, D. J. Garrick, R. G. Snell, R. J. Spelman, and S. R. Davis. 2014 Functionally reciprocal mutations of the prolactin signalling pathway define hairy and slick cattle. Nat. Commun. 5:5861. https:// doi.org/10.1038/ncomms6861.

Liu, Z., F. R. Seefried, F. Reinhardt, S. Rensing, G. Thaller, and R. Reents. 2011. Impacts of both reference population size and inclusion of a residual polygenic effect on the accuracy of genomic prediction. Genet. Sel. Evol. 43:19. https://doi.org/10.1186/1297 -9686-43-19.

Loi, P., P. Toschi, F. Zacchini, G. Ptak, P. A. Scapolo, E. Capra, A. Stella, P. A. Marsan, and J. L. Williams. 2016. Synergies between assisted reproduction technologies and functional genomics. Genet. Sel. Evol. 48:53. https://doi.org/10.1186/s12711-016-0231-z.

Lourenco, D. A. L., I. Misztal, S. Tsuruta, I. Aguilar, T. J. Lawlor, S. Forni, and J. I. Weller. 2014. Are evaluations on young genotyped animals benefiting from the past generations? J. Dairy Sci 97:3930-3942. https://doi.org/10.3168/jds.2013-7769.

Lund, M. S., A. P. W. de Roos, A. G. de Vries, T. Druet, V. Ducrocq, S. Fritz, F. Guillaume, B. Guldbrandtsen, Z. Liu, R. Reents, C. Schrooten, F. Seefried, and G. Su. 2011. A common reference population from four European Holstein populations increases reliability of genomic predictions. Genet. Sel. Evol. 43:43. https://doi .org/10.1186/1297-9686-43-43.

MacLeod, I. M., P. J. Bowman, C. J. Vander Jagt, M. Haile-Mariam, K. E. Kemper, A. J. Chamberlain, C. Schrooten, B. J. Hayes, and M. E. Goddard. 2016. Exploiting biological priors and sequence variants enhances QTL discovery and genomic prediction of complex traits. BMC Genomics 17:144. https://doi.org/10.1186/ s12864-016-2443-6.

Mäntysaari, E., Z. Liu, and P. VanRaden. 2010. Interbull validation test for genomic evaluations. Interbull Bull. 41:17-22.

Mäntysaari, E. A., M. Koivula, and I. Strandén. 2019. Single-step genomic evaluations. J. Dairy Sci. 102(Suppl. 1):99. (Abstr.)

Matthews, D., J. F. Kearney, A. R. Cromie, F. S. Hely, and P. R. Amer. 2019. Genetic benefits of genomic selection breeding programmes considering foreign sire contributions. Genet. Sel. Evol. 51:40. https://doi.org/10.1186/s12711-019-0483-5. 
Matukumalli, L. K., C. T. Lawley, R. D. Schnabel, J. F. Taylor, M. F. Allan, M. P. Heaton, J. O'Connell, S. S. Moore, T. P. L. Smith, T. S. Sonstegard, and C. P. Van Tassell. 2009. Development and characterization of a high density SNP genotyping assay for cattle. PLoS One 4:e5350. https://doi.org/10.1371/journal.pone.0005350.

McDougal, T. 2017. Aviagen opens state-of-the-art genotyping lab. Poultry World, Genetics, News, June 29. Accessed Dec. 23, 2019. https://www.poultryworld.net/Genetics/Articles/2017/6/Aviagen -opens-state-of-the-art-genomics-lab-151432E/.

Mendel, G. 1866. Versuche über pflanzen-hybriden. Pages 3-47 in Verhandlungen des naturforschenden Vereines zu Brünn Bd. 4, 1865, Abhandlungen. Im Verlage des Vereines, Brünn, Germany. https:/ /doi.org/10.5962/bhl.title.61004.

Meuwissen, T. H. E., B. J. Hayes, and M. E. Goddard. 2001. Prediction of total genetic value using genome-wide dense marker maps. Genetics 157:1819-1829.

Mulder, H. A. 2016. Genomic selection improves response to selection in resilience by exploiting genotype by environment interactions. Front. Genet. 7:178. https://doi.org/10.3389/fgene.2016.00178.

Nani, J. P., L. R. Bacheller, J. B. Cole, and P. M. VanRaden. 2020. Discovering ancestors and connecting relatives in large genomic databases. J. Dairy Sci. 103:1729-1734. https://doi.org/10.3168/ jds.2019-17580.

Nejati-Javaremi, A., C. Smith, and J. P. Gibson. 1997. Effect of total allelic relationship on accuracy of evaluation and response to selection. J. Anim. Sci. 75:1738-1745. https://doi.org/10.2527/1997 $.7571738 \mathrm{x}$.

Nguyen, T. T. T., P. J. Bowman, M. Haile-Mariam, G. J. Nieuwhof, B. J. Hayes, and J. E. Pryce. 2017. Short communication: Implementation of a breeding value for heat tolerance in Australian dairy cattle. J. Dairy Sci. 100:7362-7367. https://doi.org/10.3168/ jds.2017-12898.

Null, D. J., P. M. VanRaden, B. D. Rosen, J. R. O'Connell, and D. M. Bickhart. 2019. Using the ARS-UCD1.2 reference genome in U.S. evaluations. Interbull Bull. 55:30-34.

Pimentel, E. C. G., C. Edel, R. Emmerling, and K.-U. Götz. 2015. How imputation errors bias genomic predictions. J. Dairy Sci. 98:4131-4138. https://doi.org/10.3168/jds.2014-9170.

Ravagnolo, O., and I. Misztal. 2000. Genetic component of heat stress in dairy cattle, parameter estimation. J. Dairy Sci. 83:2126-2130. https://doi.org/10.3168/jds.S0022-0302(00)75095-8.

Rensing, S., E. Pasman, and F. Reinhardt. 2009. Best use of conventional EBV of bull dams and combination with direct genomic values. Interbull Bull. 40:123-126.

Rexroad, C., J. Vallet, L. K. Matukumalli, J. Reecy, D. Bickhart, H. Blackburn, M. Boggess, H. Cheng, A. Clutter, N. Cockett, C. Ernst, J. E. Fulton, J. Liu, J. Lunney, H. Neibergs, C. Purcell, T. P. L. Smith, T. Sonstegard, J. Taylor, B. Telugu, A. Van Eenennaam, C. P. Van Tassell, and K. Wells. 2019. Genome to phenome: Improving animal health, production, and well-being-A new USDA blueprint for animal genome research 2018-2027. Front. Genet. 10:327. https://doi.org/10.3389/fgene.2019.00327.

Roorkiwal, M., A. Rathore, R. R. Das, M. K. Singh, A. Jain, S. Srinivasan, P. M. Gaur, B. Chellapilla, S. Tripathi, Y. Li, J. M. Hickey, A. Lorenz, T. Sutton, J. Crossa, J.-L. Jannink, and R. K. Varshney. 2016. Genome-enabled prediction models for yield related traits in chickpea. Front. Plant Sci. 7:1666. https://doi.org/10 $.3389 /$ fpls.2016.01666.

Sargolzaei, M., J. P. Chesnais, and F. S. Schenkel. 2014. A new approach for efficient genotype imputation using information from relatives. BMC Genomics 15:478. https://doi.org/10.1186/1471 $-2164-15-478$.

Schultz, N. E., and K. A. Weigel. 2019. Inclusion of herdmate data improves genomic prediction for milk-production and feed-efficiency traits within North American dairy herds. J. Dairy Sci. 102:1108111091. https://doi.org/10.3168/jds.2019-16820.

Spelman, R. 2012. Big numbers, amazing science, better dairy animal performance. Green to Gold 8(2):16-17.

Su, G., P. Ma, U. S. Nielsen, G. P. Aamand, G. Wiggans, B. Guldbrandtsen, and M. S. Lund. 2016. Sharing reference data and including cows in the reference population improve genomic predic- tions in Danish Jersey. Animal 10:1067-1075. https://doi.org/10 $.1017 /$ S1751731115001792.

Sullivan, P. G. 2019. International genomic evaluation methods for dairy cattle. Chapter 19 in Advances in Breeding of Dairy Cattle, Burleigh Dodds Series in Agricultural Science No. 72, Part 3. J van der Werf and J. Pryce, ed. Burleigh Dodds Science Publishing, Philadelphia, PA.

Sun, C., P. M. VanRaden, J. R. O'Connell, K. A. Weigel, and D. Gianola. 2013. Mating programs including genomic relationships and dominance effects. J. Dairy Sci. 96:8014-8023. https://doi .org/10.3168/jds.2013-6969.

Thomasen, J. R., A. C. Sørensen, M. S. Lund, and B. Guldbrandtsen. 2014. Adding cows to the reference population makes a small dairy population competitive. J. Dairy Sci. 97:5822-5832. https://doi .org/10.3168/jds.2014-7906.

Torkamani, A., N. E. Wineinger, and E. J. Topol. 2018. The personal and clinical utility of polygenic risk scores. Nat. Rev. Genet. 19:581-590. https://doi.org/10.1038/s41576-018-0018-x.

van den Berg, I., D. Boichard, and M. S. Lund. 2016. Sequence variants selected from a multi-breed GWAS can improve the reliability of genomic predictions in dairy cattle. Genet. Sel. Evol. 48:83. https://doi.org/10.1186/s12711-016-0259-0.

Van Doormaal, B. 2013. Researchers identify the "dominant red" gene in Holsteins. Canadian Dairy Network, Information Articles. Accessed Sep. 12, 2019. https://www.cdn.ca/document.php?id=339.

VanRaden, P. M., and J. R. O'Connell. 2018. Validating genomic reliabilities and gains from phenotypic updates. Interbull Bull. $53: 22-26$.

VanRaden, P. M., C. Sun, and J. R. O'Connell. 2015. Fast imputation using medium or low-coverage sequence data. BMC Genet. 16:82. https://doi.org/10.1186/s12863-015-0243-7.

VanRaden, P. M., M. E. Tooker, J. R. O'Connell, J. B. Cole, and D. M. Bickhart. 2017. Selecting sequence variants to improve genomic predictions for dairy cattle. Genet. Sel. Evol. 49:32. https://doi .org/10.1186/s12711-017-0307-4.

VanRaden, P. M., C. P. Van Tassell, G. R. Wiggans, T. S. Sonstegard, R. D. Schnabel, J. F. Taylor, and F. S. Schenkel. 2009. Invited review: Reliability of genomic predictions for North American Holstein bulls. J. Dairy Sci. 92:16-24. https://doi.org/10.3168/jds .2008-1514.

Weigel, K. A., P. C. Hoffman, W. Herring, and T. J. Lawlor Jr.. 2012. Potential gains in lifetime net merit from genomic testing of cows, heifers, and calves on commercial dairy farms. J. Dairy Sci 95:2215-2225. https://doi.org/10.3168/jds.2011-4877.

Wiggans, G. R., T. A. Cooper, P. M. VanRaden, C. P. Van Tassell, D. M. Bickhart, and T. S. Sonstegard. 2016. Increasing the number of single nucleotide polymorphisms used in genomic evaluation of dairy cattle. J. Dairy Sci. 99:4504-4511. https://doi.org/10.3168/ jds.2015-10456.

Wiggans, G. R., P. M. VanRaden, and T. A. Cooper. 2011. The genomic evaluation system in the United States: Past, present, future. J. Dairy Sci. 94:3202-3211. https://doi.org/10.3168/jds.2010 -3866 .

Wiggans, G. R., P. M. VanRaden, and T. A. Cooper. 2015. Technical note: Rapid calculation of genomic evaluations for new animals. J. Dairy Sci. 98:2039-2042. https://doi.org/10.3168/jds.2014-8868.

Xu, S., D. Zhu, and Q. Zhang. 2014. Predicting hybrid performance in rice using genomic best linear unbiased prediction. Proc. Natl. Acad. Sci. USA 111:12456-12461. https://doi.org/10.1073/pnas .1413750111.

Yao, C., L. E. Armentano, M. J. VandeHaar, and K. A. Weigel. 2015. Short communication: Use of single nucleotide polymorphism genotypes and health history to predict future phenotypes for milk production, dry matter intake, body weight, and residual feed intake in dairy cattle. J. Dairy Sci. 98:2027-2032. https://doi.org/ $10.3168 /$ jds. $2014-8707$

\section{ORCIDS}

P. M. VanRaden @ https://orcid.org/0000-0002-9123-7278 